\title{
EL CONCEPTO DEL YO EN LA METAFÍSICA MODERNA DEL SIGLO XVII: \\ CAMPANELLA Y DESCARTES
}

\section{Paolo Ponzio*}

Hannah Arendt en el capítulo dedicado a la Edad moderna de Vida activa, justamente afirma que Descartes "es el padre de la filosofía moderna, así como Galileo es el antepasado de la ciencia moderna"1.

Comenzar, por lo tanto, la cuestión del sujeto con Descartes parece del todo normal, casi al límite de la banalidad. Sin embargo, si atendemos a lo que ocurre en Europa entre el siglo XV y el siglo XVII, notamos ante todo algunas señales distintivas que conducirán luego inexorablemente al cogito cartesiano. En realidad, si se reelaborara la historia del pensamiento de estos siglos, no se podría no tener en cuenta las muchas almas que subyacen al panorama cultural de la época y que han determinado la mentalidad y el curso filosófico de los siglos futuros, aun cuando -como en el caso de la filosofía de Tommaso Campanella - tal pensamiento no encontrará los favores de la crítica filosófica sucesiva, resultando de este modo derrotado en las confrontaciones del camino de la historia, la cual de modo cruel determina vencidos y vencedores de las partidas culturales de cada época.

Y no obstante esto -como intentaré demostrar- también el concepto de subjetividad campanelliano en un cierto modo nos pertenece.

De Tommaso Campanella leeré solamente algunos fragmentos extraídos del primer libro de su Universalis Pbilosopbia, su Metafísica. No se trata aquí de demorarnos en las peripecias de esta obra, reescrita por el filósofo por lo menos cinco veces, o de describir su estructura: como es

\footnotetext{
Profesor de la Facultad de Letras y Filosofía, Università degli studi di bari, Italia. ponzio@filosofia.uniba.it

${ }^{1}$ Arendt, H., The Human Condition, The University of Chicago Press, Chicago 1958 [trad. castellana: Arendt, Hannah: La condición bumana, Paidós, Barcelona, 1993, p. 299].
} 
notorio la obra está subdivida en tres partes intituladas por el autor principia sciendi, principia essendi, principia agendi ${ }^{2}$.

El tratamiento del ser, por lo tanto, está precedido por una primera parte dedicada a los principios del saber y de las ciencias. No se puede conocer nada del ente real si primero no se conoce aquello que se puede conocer.

El Proemio inicial de la obra aclara cuáles son los términos del problema:

"Sólo en Dios hay verdad, en cuanto Él es absolutamente poderoso, sabio y bueno. Todo hombre, al contrario, es mentiroso, ya sea porque le falta poder o porque es ignorante o porque por maldad quiere decir lo falso en lugar de lo verdadero"'3.

Será necesario, por lo tanto, demoler todas las doctrinas humanas e indagar la posibilidad y la forma del conocer. La condición inicial es, pues, la de la duda, una duda universal, que deviene para Campanella una verdadera hipótesis de trabajo filosófico que se traducirá en la lista de catorce posibles aporías o dudas del conocer que caracterizan el primer capítulo de la obra metafísica. La cuestión de la criticidad del saber viene así colocada como prioritaria respecto a todo otro tratamiento. Estas catorce dudas pueden ser subdivididas según cuatros grupos temáticos:

1. La relatividad del conocer: la cuestión del singular y del universal (art. 1-2)

2. La relatividad del sentido: mutabilidad del sujeto y de la realidad (art. 3-8).

3. La duda concerniente a la relación, en el acto cognoscitivo, entre el cognoscente (sujeto de la acción) y lo conocido (objeto de la acción). Tal acción se realiza a través de una pasión o información en la cual el sujeto, recibiendo el objeto, se hace objeto y se anula como sujeto y viceversa, desde el punto de vista del sujeto. Éste, soportando una pasión en sí, no puede hacerse sí mismo en cuanto

2 Cfr. Campanella, T., Universalis philosopbiae seu metaphysicarum rerum iuxta propria dogmata, partes tres, libri 18, apud Langlois, Parisiis, 1638 (ed. crit. del libro primero a cargo de P. Ponzio, Levante ed., Bari, 1994).

${ }^{3}$ Ivi, lib. I, p. 1 [ed. crit., p. 17]. 
que viene a faltar el otro término del acto cognoscitivo, el objeto (art. 9-10).

4. La imposibilidad del saber a causa de los contrastes y de los errores de los filósofos y de las ciencias, confirmada ulteriormente por la inadecuación del lenguaje humano (art. 11-14)4

Ejemplificando mucho, me parece interesante leer cómo se introduce el primer tipo de duda:

"No hay ciencia ni sabiduría para los hombres, porque las cosas que conocemos son una mínima parte respecto a aquellas que ignoramos. Nosotros no conocemos ni siquiera la mínima parte de las cosas que pensamos conocer, desde el momento en que para conocer una cosa verdaderamente sería necesario conocer hasta el infinito, y eso no es posible"5.

La imposibilidad del conocimiento conduce así a tomar en consideración la posición del pensamiento escéptico. El diálogo que Campanella instaura con el escéptico es tan importante como placentero, ya que, de modo irónico, desenmascara todas las hipocresías de un pensamiento que no quiere atenerse al dato de la realidad. Así también de aquel que duerme o de aquel que es loco se puede decir que se engaña con cosas que otros afirman como verdaderas.

¿Cómo salir, por lo tanto, de este momento aporético? ¿Cuál puede ser el conocimiento certísimo y universal a partir del cual no se da el error y a partir del cual es posible proceder a la construcción del saber?

Antes de responder a tales preguntas, me permito proponer una cuestión preliminar: cómo interpretar este momento de duda propedéutica en Campanella. Si para algunos historiadores de la filosofía esta posición de duda no puede de ninguna manera ser puesta en relación con la posición de duda de Descartes, para otros -en cambio- esta temática de la duda campanelliana no puede sino ser puesta en estrecha conjunción con la posición cartesiana. Es necesario, sin embargo, considerar algunas

${ }^{4}$ Cfr. todo el capítulo primero del libro I de la metafísica de T. Campanella, pp. 629 [ed. crit., pp. 44-191]

${ }^{5}$ Campanella, C., Universalis philosopbiae seu metaphysicarum rerum..., p. 6 [ed. crit., p. 45]. 
diferencias sustanciales. $\mathrm{Si}$, en efecto, la posición de la duda es análoga, la diferencia de pensamiento que brota de ella puede explicarse sólo con un diverso concepto de realitas. Si para Descartes la realidad tiene como presupuesto propio el concepto de essentia obiectiva, o idea, en Campanella también tal essentia debe ser indagada de la misma manera que corresponde a la metafísica la indagación sobre el esse universalissimum que las otras ciencias particulares dan por adquirido. Lo que Campanella presupone en cambio es el origen de la misma realidad, el hecho de que la realidad sea creada. El concepto de creación, en efecto, escapa a la pregunta sobre el conocimiento; le es precedente. Escribe en efecto:

"Queriendo conocer la verdad sobre las cosas humanas y divinas, es necesario confiarse a un doctor de fe indubitable, y no encontramos ninguno a no ser Dios"6.

Es decir, se trata de presuponer a Dios en cuanto racionalidad absoluta. Si la realidad posee una verdad, ésta no puede sino derivarse de Dios que la ha querido y creado.

Por lo tanto -podemos concluir- en Campanella la existencia de Dios es puesta con anterioridad a todo conocimiento, así como es cierto que la realidad que me circunda es creada, me ha sido dada, es donada. Para Campanella no hay márgenes para pensar la hipótesis de un Dios engañador.

Pero Dios, en todo caso, es garante (para usar un término caro a la filosofía racionalista moderna) de la veracidad de la realidad. $Y$ esto no elimina el drama del conocimiento, de la posibilidad del saber por parte del hombre: más aún, en algunos sentidos lo agudiza, porque no obstante la existencia de Dios y de la realidad, no parece poder haber para nosotros conocimientos ciertos. Si de las cosas reales, en efecto, se puede establecer un cierto conocimiento parcial mediante el carácter de relatividad del conocimiento sensible -según el cual es posible conocer las cosas en sus distinciones y relaciones y entender que todo ente tiene una particular medida cognoscitiva - no parece haber algún conocimiento cierto per se. Vale decir, si las cosas existen, hay consecuentemente también saber, porque el saber se dirige a las cosas; pero este saber es un conocer por relaciones, no un conocimiento de las cosas tal como ellas son. El hombre posee sin duda

${ }^{6}$ Ivi, p. 2 [ed. crit., pp. 21-22]. 
la capacidad de conocer las cosas en su ser transitorias, y sin embargo hay en él el deseo de un conocimiento que tenga el gusto de la certeza y de la verdad.

Retornamos así a la pregunta anteriormente formulada: ¿Existe algún conocimiento cierto, que no dé error alguno? ¿Cómo se yergue el dispositivo del conocimiento humano?

Como ya hemos dicho, Campanella ya ha expuesto la refutación tradicional del escepticismo, pero tal refutación no puede ser más que una medicina parcial, preparándose así a suministrar el argumento principal e inexpugnable para la fundación de la certeza. Tal argumento es el ponerse inequívoco de la autoconciencia que Campanella mismo declara derivar del De civitate Dei y del De Trinitate de Agustín?:

"tres son las cosas más ciertas para nosotros, y eso es lo que somos, sabemos y queremos. Nosotros, en efecto, sin duda y sin falsedad sabemos que somos, que amamos nuestro ser y nuestro saber; y en estas tres certezas no hay ninguna falsedad que pueda turbarnos, en cuanto que se yerra sobre aquellos objetos de los cuales tenemos conocimiento mediante las imágenes y los impulsos que nos provienen de ellos mismos. [...] Sin embargo de nuestro ser y de nuestro saber y de nuestro querer no existe imagen o movimiento alguno en la fantasía, sino que son una presencia perenne (presentia perennis)"8.

Los desarrollos de este principio siguen casi a la letra el recorrido agustiniano:

"Para mí es certísimo que soy. Si lo afirmas, posees esta certeza; si lo niegas y dices que me engaño, reconoces evidentemente que soy; no pueden engañarme, en efecto, si no soy. Del mismo modo por el hecho que sé que soy no me engaño [...] y así como sé que soy, sé que sé que soy, y aprecio y amo estos dos elementos, vale decir que soy y que me conozco. Por lo tanto, es necesario agregar un tercer elemento, vale decir el amor por tal ser y por tal conocimiento. $Y$ nadie puede decir que me engaño cuando digo que amo, que soy y que sé, dado que en estas cosas

${ }^{7}$ Cfr. Agustín, De civitate Dei, 11.26.

${ }^{8}$ Campanella, T., Universalis philosophiae seu metaphysicarum rerum..., p. 32 [ed. crit., p. 201]. 
que amo ha sido probado que no me engaño, es decir en el ser y en el saber; y aun cuando fuesen falsas aquellas cosas, sería siempre verdadero que yo amo cosas falsas. Es por lo tanto verdadero e infalible que yo las amo. Ya que, sean verdaderas o falsas, el amor es verdadero. Y no hay quien no quiera ser feliz; por lo tanto no hay nadie que no quiera ser; es, por lo tanto, certísimo este amor, así como el ser y el saber"9.

He aquí, por fin, hallado este primer principio certísimo: la noticia de nuestro ser, de nuestro conocer y de nuestro amar. $Y$ tal conocimiento difiere de los otros por su particular condición: la conciencia, en efecto, no hace otra cosa que recoger la presencia perenne del propio poder ser, del propio saber y del propio amar, vale decir, no hace otra cosa que recoger la propia y constitutiva esencia. El poder ser, el saber y el amar, en efecto, no son tres res o quidditas distintas, no son realidades participativas de la conciencia, sino realidades constitutivas, esencialidades de la misma esencia. No constituyen tres actos diferentes, sino que son tres primariedades -éste es el nombre que Campanella da a los tres elementos- de un único acto ${ }^{10}$.

Es necesario, finalmente, notar como tal explicación de la autoconciencia $^{11}$ tiene un importante corolario: para Campanella, en efecto, no parece ser suficiente deducir la primera certeza en base al solo riguroso concepto de la autoconciencia; así como para Agustín, es necesario ampliar la justificación de la autoconciencia a través del deseo de sí. Si es verdad que en el orden del ser el amor procede del saber y del poder ser (puesto que no se ama aquello que es desconocido o aquello que es imposible), mientras el saber procede de la potencia (puesto que no se conoce lo que no se puede conocer, mientras que se conoce también lo que no se ama), en el orden del conocimiento, el amor lleva la prioridad absoluta porque el amor es el punto de partida -el motor- de todo conocimiento. Todo ser, efectivamente, se conoce a sí mismo porque se ama a sí mismo, despreciando el propio contrario a partir del cual sería destruido.

\footnotetext{
${ }^{9}$ Ibidem [ed. crit., pp. 201-203].

${ }^{10}$ Cfr. Femiano, S., La metafisica di Tommaso Campanella, Marzorati, Milano, 1968, pp. 187-198.

11 Para la tematica de la autoconciencia, cf. R. Amerio, "Forme e significato del principio di autocoscienza in Sant'Agostino e Tommaso Campanella", Rivista di filosofia neoscolastica, 32, 1931, pp. 75-114.
} 
He aquí establecido el carácter del cogito campanelliano. Pasemos ahora, más brevemente, al cogito cartesiano, para poder sacar algunas reflexiones finales.

Visto que sobre el cogito de Descartes hay tantos volúmenes como para hacer desistir a cualquier investigador en la empresa de iniciar una indagación exhaustiva, me limitaré a indicar aquellos que ya han sido considerados como los principales modelos interpretativos del cogito ${ }^{12}$.

El primer modelo se lo puede deducir del célebre "cogito ergo sum", presentando el cogito como una deducción silogística ${ }^{13}$. En realidad, Descartes mismo ha criticado tal lectura del cogito. $\mathrm{Y}$ aun en el caso de que se aceptara tal formulación, será necesario remarcar el carácter de evidencia del acto de pensar. Es este acto, en efecto, el que transforma el enunciado abstracto en una existencia ya no más lógica, sino ontológica. Es lo que Descartes mismo escribe al Marqués de Newcastle en marzo de 1648:

“SSabe usted que tiene menos certeza de la presencia de los objetos que ve, que de la verdad de la proposición: yo pienso por lo tanto yo soy? Por lo tanto, este conocimiento no es un resultado de su razonamiento, $y$ no es tampoco una instrucción de vuestros maestros, sino que su espíritu ve esta verdad, la siente, la tiene en la mano"14.

Es por lo tanto por un intuitus que se acoge el descubrimiento de la existencia.

Pasemos ahora al segundo modelo interpretativo, llamado performativo. Esta es una tesis presentada por Jean Austin y seguidamente por Jaako Hintikka ${ }^{15}$. El performativo es un enunciado que no sólo tiene la función de constatar alguna cosa sino también de realizar aquello que dice. Por ejemplo,

12 En esta explicación de los modelos del cogito, se sigue la lectura de Jean-Luc Marion, Questions cartésiennes II, PUF, Paris, 1996, pp. 3-47.

${ }^{13}$ Cfr. Descartes, R., Discours de la methode, in Oeuvres de Descartes, publiées par Ch. Adam e P. Tannery, Cerf, Paris, 1902, vol. 6, p. 32. Para esta interpretación, cf. M. Guerolt, Descartes selon l'ordre des raisons, 2 vol., Aubier, Paris, 1953.

${ }^{14}$ Cfr. Oeuvres de Descartes, publiées par Ch. Adam e P. Tannery, Cerf, Paris, 1902, t. V, p. 138.

15 Cfr. Hintikka, J., “Cogito Ergo Sum': Inference or Performance?”, The Philosopbical Review, 71, 1962, pp. 2-32; Id., "Cogito Ergo Sum' as an Inference and a Performance”, The Philosophical Review, 72, 1963, pp. 487-496. 
un juez, pronunciando una sentencia de condena, efectivamente condena al imputado; o en el examen final de licenciatura, cuando se dice al candidato que ha superado el examen de licenciatura el candidato se ha efectivamente licenciado. Hay un texto clásico de las Meditaciones de Descartes que es interpretable de este modo:

"así por lo tanto, después de haber reflexionado mucho, debe finalmente tenerse por seguro que la afirmación, Yo soy, yo existo, es necesariamente verdadera toda vez que la pronuncio, o que la mente la concibe"16.

Aquí es evidente el carácter performativo del enunciado. Hay, sin embargo, un carácter de la teoría performativa que en el caso del cogito no parece ser respetado. Es necesario, en efecto, que aquel que profiere tal enunciado sea cualificado: el juez, el decano, etc. En el caso del cogito la cuestión es la siguiente: ¿el ego tiene tal cualificación? ¿Tiene la cualidad de producir la existencia, visto que antes de pronunciar el ego sum, ego existo, dudaba de la propia existencia? Todo enunciado performativo, en efecto, presupone que quien lo pronuncia existe y tiene la cualificación ontológica que parece faltar al ego.

Llegamos así al tercer modelo, que es sin duda el más conocido ya que será retomado por Kant y por Heidegger. Según lo que dice Kant, «el yo pienso debe poder acompañar a todas mis representaciones, ya que si no fuese así vendría representado en mí algo que no podría ser en absoluto pensado» ${ }^{17}$, o según la fórmula de Heidegger «cogito me cogitare rem» ${ }^{18}$, retomado luego en el libro sobre Nietzsche a propósito del cogito cartesiano: " ego cogito me cogitare». La tesis interpretativa es la siguiente: hay una exigencia formal fundamental según la cual yo no puedo representar un objeto en la conciencia sin representarme antes la conciencia misma. La interioridad del

16 "Adeo ut, omnibus satis superque pensitatis, denique statuendum sit boc pronuntiatum, Ego sum, ego existo, quoties a me profertur, vel mente concipitur, necessario esse verum'. Descartes, R., Meditationes de prima philosophia, in Oeuvres de Descartes, publiées par Ch. Adam e P. Tannery, Cerf, Paris 1902, vol. 7, p. 25.

17 Kant, I., Crítica de la razón pura, Alfaguara, Madrid, 1996, trad. Pedro Ribas, Deducción trascendental, $₫ 16$.

${ }^{18}$ Heidegger, M., Sein und Zeit, $\ 82$ (tr. Ser y tiempo, trad., prol. y notas de J. E. Rivera, Editorial Universitaria, Santiago de Chile, 1998 p. 441); Id., Nietzsche, II, Neske, Pfullingen 1961, p. 153. (tr, Nietzsche, II, trad. Juan Luis Vermal, Ediciones Destino, Barcelona, 2001, p. 149) 
cogito y la existencia del ego son por lo tanto la condición de posibilidad del pensamiento de un objeto cualquiera: es aquello que decía Husserl cuando afirmaba que sólo la conciencia tiene un ser absoluto, mientras que el mundo de los objetos posee solamente un ser relativo. Sin embargo también tal modelo posee algunos inconvenientes, más aún, el mismo Descartes, en las respuestas a la objeción séptima del jesuita Bourdin, anticipa la fórmula heideggeriana del cogito me cogitare:

"Cuando nuestro autor (Bourdin) dice que no basta que una cosa sea una sustancia pensante para estar por encima de la materia y ser completamente espiritual, lo cual él exige para que algo pueda ser llamado propiamente con el nombre de espíritu; sino que además de eso se requiere que, con un acto reflejo sobre su pensamiento, ella piense que piensa (cogitet se cogitare), o que tenga una conciencia interna de su pensamiento, se engaña como hace aquel albañil cuando dice que un hombre experimentado en la arquitectura debe, por medio de un acto reflejo, considerar que él tiene la experiencia, antes de poder ser arquitecto"19.

Llegamos así al cuarto modelo interpretativo que podemos denominar "del sentir". Cuando hablamos del cogito como deducción silogística dijimos que Descartes piensa al cogito como un intuitus de la mente que ve, que siente, que tiene en las manos esta verdad. La cuestión es la siguiente: ¿cómo puede "sentir" esta verdad? ¿Qué es este sentir? Sentir es lo contrario del representar. Es Michel Henry quien, en su libro Généaologie de la psychanalyse ${ }^{20}$, sostiene que la forma suprema del cogitar cartesiano es precisamente el sentir. Hay muchos textos que nos indican este nexo. En la segunda meditación se lee en un cierto punto ego sum qui sentio:

'Yo soy aquello mismo que siente, o que percibe las cosas corpóreas, como a través de los sentidos: en efecto, ahora ciertamente veo la luz, oigo un estruendo, siento calor. Eso es falso, en efecto, duermo. Lo que es cierto es que me parece ver, oír, advertir el calor. Esto no puede ser falso; y esto es lo que propiamente en mí se llama sentir, y esto [...] no es otra cosa que pensar"21.

${ }^{19}$ Descartes, R., Meditationes de prima philosopbia, ed. cit., p. 559.

${ }^{20}$ Cfr. el capitulo 3 de M. Henry, Généaologie de la psychanalyse, PUF, Paris, 1985.

${ }^{21}$ Descartes, R., Meditationes de prima philosopbia, ed. cit., p. 29. 
Pensar es sentir, el contenido del pensar puede también ser dudoso, pero el hecho de pensar y de sentir inmediatamente que yo pienso no puede ser puesto en duda. Hay por lo tanto -como afirma Henry- un sentir originario del pensamiento. Aquello que siento no es un objeto, sino el pensamiento mismo. No estoy en una relación de representación y de reflexión sobre mi pensamiento, sino en una relación de inmediatez, es decir en una relación de "sentirse a sí mismo". La dificultad de este modelo es, sin embargo, evidente: Descartes no dice «yo siento que yo pienso», es decir no pone el sentir al mismo nivel del cogito. $\mathrm{Y}$ es por esto que tal lectura del cogito puede no ser del todo suficiente.

Pasemos ahora al último modelo interpretativo que deducimos directamente de las Questions cartésiennes (vol. II) de Jean-Luc Marion, y que podríamos definir "modelo dialógico". La idea de Marion es por demás sugestiva: el momento inicial es cuando Descartes al inicio de la segunda meditación dice:

“¿Pero de dónde sé que no hay nada distinto de todas las cosas que he pasado revista más arriba sobre lo cual no habría ni siquiera un mínimo motivo de duda? ¿No hay acaso algún Dios, o como se lo quiera llamar, que insinúa en mí estos pensamientos?”22.

Aquello que emerge aquí es el hecho que mientras el ego y Dios no existen todavía, Descartes advierte la hipótesis de que las ideas y los pensamientos provienen de algún Dios. Vale decir, parece ser hipotéticamente una estructura dialógica entre un Dios del cual no se ha todavía mostrado o demostrado la existencia y un yo que sin duda no existe todavía. Y sin embargo se trata de una estructura dialógica. Y tal estructura continúa en las sucesivas preguntas, al punto de poder afirmar que el yo para fundarse debe necesariamente entrar en relación consigo mismo o con otro. El pensamiento es por lo tanto un advenimiento que existe en relación con otro. Se trata de un acto en el cual el primer pensamiento es el pensamiento que recibo "pero entonces ciertamente no hay duda de que yo existo si él me engaña; y que me engañe todo lo que pueda, pues no logrará jamás sin embargo hacer que yo no sea nada en tanto piense ser algo"23.

\footnotetext{
22 Ivi, p. 24.

23 Ivi, p. 25.
} 
Si él me engaña, yo existo. Es el pensamiento que el otro me envía el que constituye mi primer pensamiento, mi primera evidencia. El yo por lo tanto existe porque está envuelto en un diálogo: es este diálogo el que lo hace existir. Pero, nos preguntamos, ¿con quién acontece este diálogo? No es con Dios, porque este otro me engaña, pero el otro que no es Dios no tiene otro nombre, más bien no tiene ningún nombre: Descartes mismo dice no conocerlo. Sería este, entonces, el único caso de un diálogo entre un yo que no existe todavía y un otro del cual no conozco la existencia, que me permite probar mi pensamiento, y por lo tanto existir. El cogito no es jamás un cogito solitario: la estructura originaria de la conciencia de sí es una estructura dialógica.

No sé si el modelo interpretativo de Marion pueda resultar del todo aceptable (y ciertamente no estará falto de insuficiencias), sin embargo me parece interesante detenerse sobre algunas consecuencias que podrían ser extraídas del cogito cartesiano en diálogo y que de alguna manera pueden reconducirnos a aquello que se decía antes de la autoconciencia campanelliana. El diálogo del yo que no existe todavía se realiza con alguna alteridad de la cual no sabemos nada, pero de la cual suponemos alguna existencia, incluso malvada. Es por lo tanto, necesario suponer la existencia de algún ser del cual recibo el pensamiento. También en Descartes el yo parece no hacerse por sí mismo; es necesario que haya alguien que nos haga ser, que nos conduzca al ser: yo soy porque tú me baces. Aun no conociendo nada de este tú -aún siendo incógnita esta presencia, un tú sin rostro- e incluso en la hipótesis del engaño, el yo no puede hacer menos que darse cuenta de la presencia de algún ente otro que sí, que la tradición siempre ha identificado con una alteridad infinita, con Dios.

Se podría decir que Descartes, a diferencia de Campanella, procede en su discurso filosófico en modo lógico -desde el yo, a Dios, a las cosasdejando entre líneas la precedencia del orden ontológico que resulta por el contrario decisiva en el discurso campanelliano. El Dios bueno que parece entrar sólo en un segundo momento en el filosofar cartesiano, de algún modo anticipa su presencia en el interior de esta estructura dialógica del ego.

Existe sin embargo un factor que parece hacerse extraño al pensamiento de Descartes y desde él invadir toda la historia del pensamiento, tanto que se podría decir que él constituye tal vez uno de los signos más distintivos de la modernidad: la pérdida del componente afectivo 
del conocer; el conocimiento de algo no consiste más en el ser "afectado por", en el sufrir el contragolpe atractivo de la realidad, sino que consistirá en la suma de los datos mensurables y clasificables del método matemático. Aquello que todavía en Campanella determina de modo inequívoco el empuje inicial de todo conocer, el origen del cual depender para que toda confrontación con la realidad produzca resultados verdaderos, en Descartes se transforma en obstáculo, en error. Cuando en efecto, en la IV Meditación Descartes habla de la función de la voluntad en el interior del iudicium, aun afirmando la imposibilidad de que tal voluntad sea causa de error de por sí, localizará justamente en el uso de esta facultad el mayor riesgo de error, porque aquella está desvinculada de los rígidos y esquemáticos cánones en los cuales es posible confinar al intelecto. $\mathrm{Y}$ justamente por esta estructura "libre" de la voluntad, justo por esta reconocida capacidad infinita, es necesario retener «la voluntad de manera que ésta se extienda sólo a las cosas que el intelecto representa de forma clara y distintas ${ }^{24}$. De este modo no habrá ninguna posibilidad de caer en el error. Pero, ¿de qué le sirve al hombre una realidad que no puede abrazar, de la cual no puede reconocer el origen?

Es éste el alto precio que pagamos a la modernidad: la presunta afirmación "solipsística" de la subjetividad hace de tal modo que la realidad pierda interés, aun más, que se pierda la realidad misma produciendo como decía Hannah Arendt en Vida activa, citando a Whitehead - «el efecto del retraerse del sentido común» ${ }^{25}$.

(Traducción del italiano: Federico Ignacio Viola; supervisión: Dr. Fernando Bahr)

\section{Resumen}

El concepto del yo en la metafísica moderna del siglo XVII: de la autoconciencia de Tommaso Campanella al Cogito cartesiano. Éstas son las coordenadas entre las que es posible indagar el concepto del yo en la edad moderna. El presente artículo, por tanto, intenta analizar las opciones filosóficas de estos dos autores capitales en la formación de la filosofía moderna, para poder preguntarse, finalmente: cuál es el

${ }^{24}$ Ivi, p. 61.

${ }^{25}$ Arendt, H., The Human Condition, cit., cap. 6 [trad. castellana: Arendt, Hannah: La condición bumana, Paidós, Barcelona, 1993, p. 309] 
precio que pagamos a la modernidad? La presunta afirmación "solipsista" de la subjetividad induce a que la realidad pierda interés; más aún, a que se pierda la realidad misma produciendo -como decía Hannah Arendt en Vida activa, citando a Whitehead- "el efecto del retraerse del sentido común".

Palabras clave: "Descartes", “Campanella”, “yo”, “metafísica moderna”.

\begin{abstract}
The concept of ego in the modern metaphysics of the XVII century: from the selfconsciousness of Thomas Campanella to the cogito of Descartes. This are the coordinates within which it is possible to investigate the concept of the ego in the modern age. The present article, therefore, tries to analyse the philosophical choices of these two great authors of modern philosophy, to be finally able to ask: Which is the price we pays to modernity? This alleged "solipsistic" assertion of subjectivity in way encourages the loss of interest in reality; even more, the loss of reality itself producing -as Hannah Arendt stated in The Human Condition, quoting Whitehead "the effect of withdrawing from the common sense".

Key words: "Descartes", "Campanella", "ego", "modern metaphysics".
\end{abstract}

